Trauma Surgery \& Acute Care Open

\title{
Step-up approach for the management of pancreatic necrosis: a review of the literature
}

\author{
Melanie Kay Sion, ${ }^{\oplus 1}$ Kimberly A Davis ${ }^{\circledR 2}$
}

'Surgery, Yale University, New Haven, Connecticut, USA

2Surgery, Yale School of Medicine, New Haven, Connecticut, USA

\section{Correspondence to} Dr Melanie Kay Sion, Surgery, Yale University, New Haven, CT 06520, USA; melanie.sion@ yale.edu

Received 1 March 2019 Revised 19 April 2019 Accepted 30 April 2019 (c) Author(s) (or their employer(s)) 2019. Re-use permitted under CC BY-NC. No commercial re-use. See rights and permissions. Published by BMJ.

To cite: Sion MK, Davis KA. Trauma Surg Acute Care Open 2019;4:e000308.

\section{ABSTRACT}

Infected necrotizing pancreatitis is a challenging condition to treat because of the profound inflammatory response these patients undergo which can then be exacerbated by interventions. Treatment of this condition has evolved in timing of intervention as well as method of intervention and includes less invasive options for treatment such as percutaneous drainage and endoscopic drainage, in addition to less invasive endoscopic and video-assisted or laparoscopic debridements. The precise optimal treatment strategy for these patients is an ongoing topic of discussion and may be different for each patient as this is a heterogenous condition.

\section{INTRODUCTION}

Acute pancreatitis (AP) is a heterogenous condition that has the potential to be life threatening. In 2017, AP resulted in 2770 deaths at a rate of 0.9 per 100 000 in the USA. ${ }^{1}$ According to the revised Atlanta Criteria of 2012, AP is classified as mild, moderately severe, and severe. ${ }^{2}$ At its worst, AP evolves into infected necrotizing pancreatitis with organ failure which can have a mortality rate of $35 \% .^{3}$ The most common causes of pancreatitis are gallstone disease and excessive alcohol consumption, however a variety of factors are likely at play with regard to which persons will manifest $\mathrm{AP}^{4}$ Because infected necrotizing pancreatitis is an arduous condition to treat, substantial effort is being made to analyze the effectiveness of various treatment strategies with the goal of improving survival and minimizing anatomic and physiological sequelae.

\section{SPECTRUM OF AP}

The 2012 revised Atlanta Criteria defined grades of severity and types of AP. These distinctions are important to identify patients who are at risk for severe disease so that they can be carefully monitored and supported, in addition to identifying those patients who may have a protracted disease course and need invasive intervention. Mild AP is self-limiting, does not lead to organ failure, and does not have local or systemic complications. ${ }^{2}$ Moderately severe AP causes transient organ failure that resolves within 48 hours and/or has local complications such as fluid collections or causes exacerbation of comorbid conditions. ${ }^{2}$ Severe AP is defined by persistent single or multiple organ failure lasting greater than 48 hours. $^{2}$ Two separate types of pancreatitis were redefined in 2012 as acute edematous pancreatitis and acute necrotizing pancreatitis, the latter often resulting in a significant inflammatory response and has greater potential for a superinfection.

Approximately $5 \%$ to $10 \%$ of patients develop necrotizing pancreatitis. If fluid and necrotic pancreatic or peripancreatic debris form collections within 4 weeks of presentation they are termed acute necrotic collections. ${ }^{2}$ After 4 weeks these collections mature, become encapsulated and are then termed walled-off pancreatic necrosis. These can be in a number of locations throughout the abdomen in various patterns and sizes (see figures 1-5). Infection of these collections often necessitates invasive intervention. In the past, tangible proof of infection via an image-guided fine needle aspiration or gas seen within the collections on CT scan was preferred to justify intervention. Protocols have been modified to forgo this step based on the suspicion of infection, particularly in patients who will likely undergo an intervention and can have cultures taken at that time. ${ }^{56}$

\section{HISTORY OF EARLY OPEN NECROSECTOMY}

Historically patients with necrotizing pancreatitis would undergo early laparotomy and necrosectomy. This has changed dramatically during the last 20 years. Early intervention was proven to be detrimental and is now reserved for cases with evidence of hemorrhage not amenable to interventional embolization, abdominal compartment syndrome, or hollow viscus perforation. It was found that outcomes for patients with severe pancreatitis improved by avoiding exacerbation of the inflammatory state with surgery. A prospective randomized study in 1997 initially showed the marked decrease in mortality with delayed surgical intervention and ended the study early for this reason.? Another early study looked at three separate time periods where different practice patterns prevailed and compared mortality rates. ${ }^{8}$ They found that similarly, the latest time period which delayed intervention the longest had the lowest mortality. ${ }^{8}$ Subsequent to these studies the question of management of known infected necrosis was addressed with a retrospective review of 53 patients and a systematic review of 10 studies as well as a large prospective study which again demonstrated that delayed intervention was found to have the lowest mortality. ${ }^{9}{ }^{10}$ Today national guidelines continue to reflect this sentiment.

\section{MINIMALLY INVASIVE THERAPEUTIC OPTIONS}

In step with most of medicine, minimally invasive strategies have been explored and employed in treating infected pancreatic necrosis. With the 


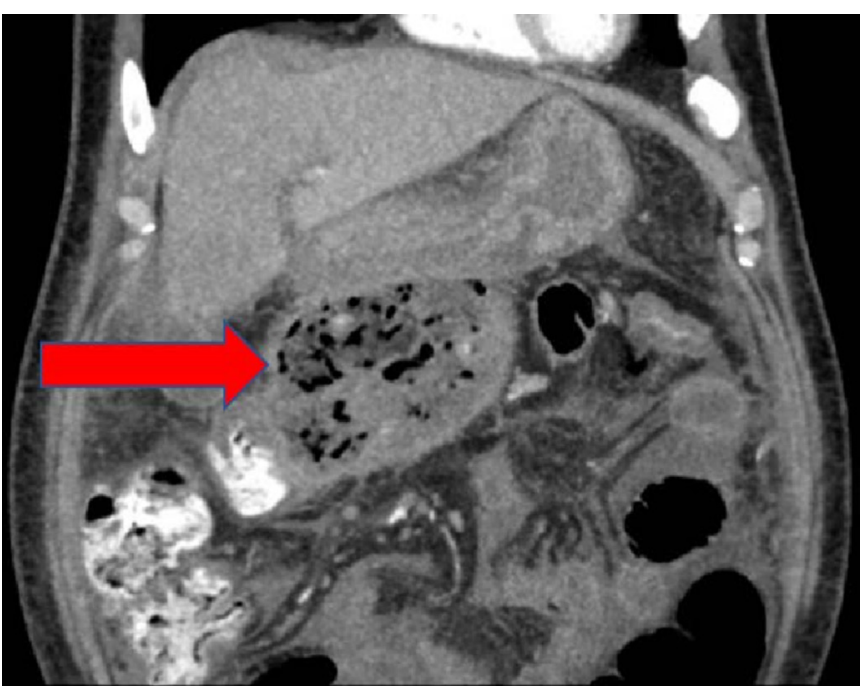

Figure 1 Periduodenal collection (red arrow).

goal of lessening the inflammatory response from open surgery and the related morbidity such as hernia, a number of techniques have proliferated internationally. The optimal treatment strategy for infected necrotizing pancreatitis remains unclear and ongoing effort across multiple disciplines is taking place to add to the literature.

The Pancreas Network of New Zealand created a well-organized classification system for the many therapies for necrotizing pancreatitis, which is termed the 'VRP Classification' standing for visualization (eg, radiologic, endoscopic, open), route (eg, percutaneous retroperitoneal/transperitoneal, per-os transmural/ transpapillary), and purpose (eg, drainage, lavage, debridement). ${ }^{11}$ This is a useful taxonomy system to consider because the precise technique behind many of these procedures is often not clear in the literature and can lead to miscommunication and inability to make comparisons. ${ }^{11}$

The most common current treatment options for infected necrotizing pancreatitis include but are not limited to:

- Percutaneous retroperitoneal or transperitoneal drainage.

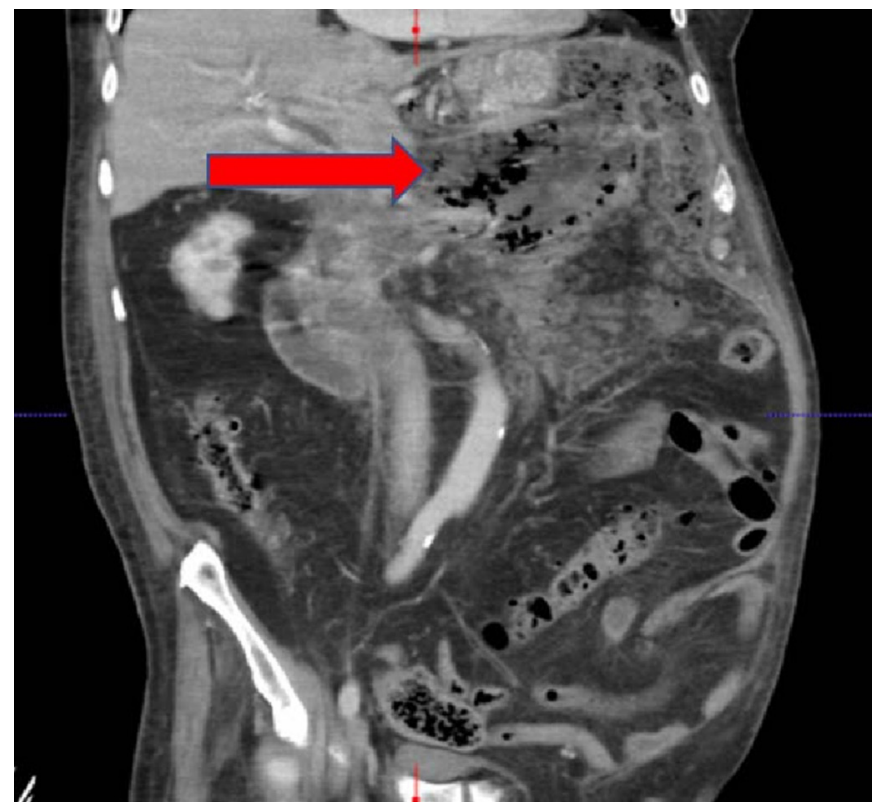

Figure 2 Collection confined to the lesser sac (red arrow).

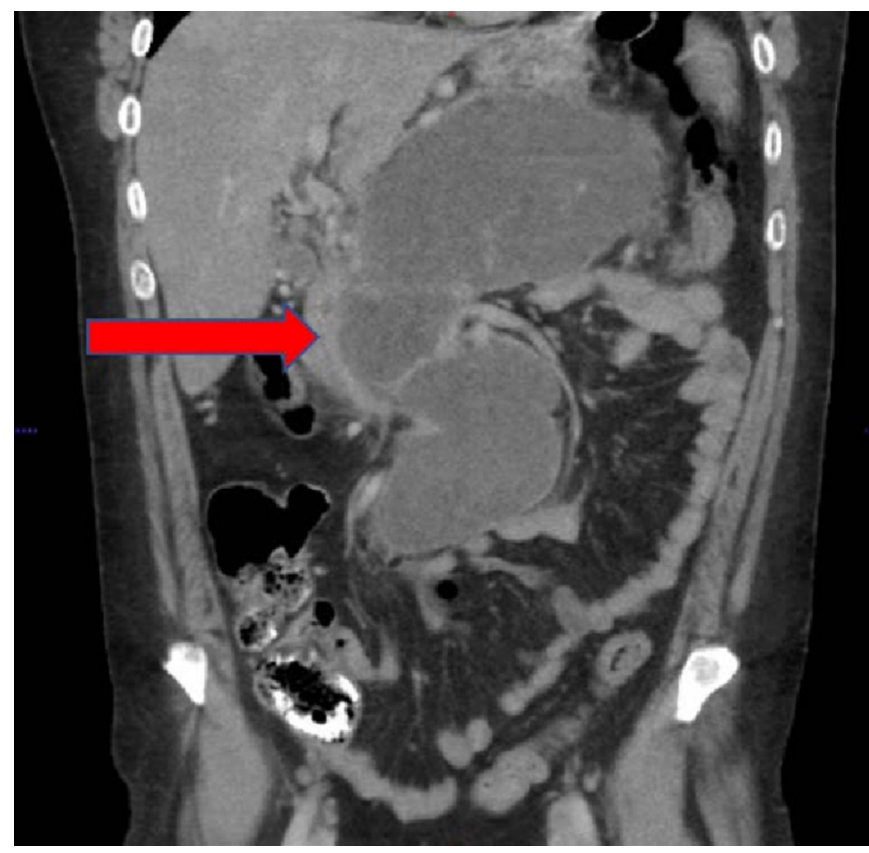

Figure 3 Collection extending to the root of the mesentery (red arrow).

- Endoscopic transmural or transpapillary drainage.

- Minimally invasive retroperitoneal necrosectomy.

- Video-assisted retroperitoneal debridement.

- Endoscopic therapy necrosectomy.

- Laparoscopic or open necrosectomy.

- Laparoscopic or open cystgastrostomy or cystojejunostomy.

\section{ADVENT OF THE STEP-UP METHOD}

Open necrosectomy was formally challenged with the PANTER trial from the Dutch Acute Pancreatitis Study Group. The term 'step-up' was coined with this trial and is used commonly across disciplines when referring to minimally invasive procedures that

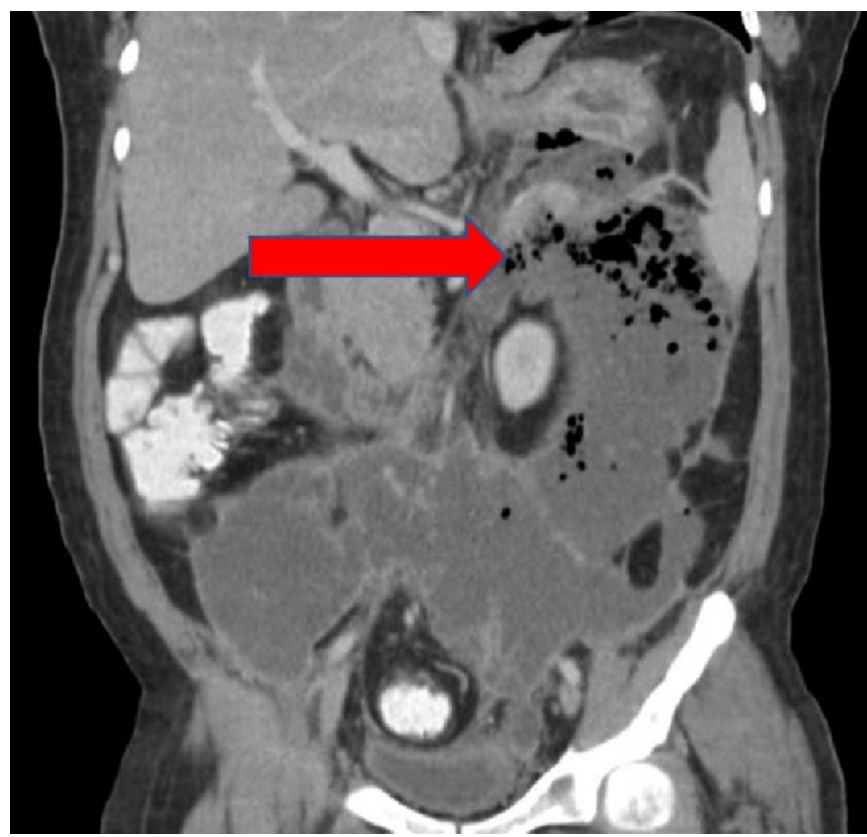

Figure 4 Collection extending down the left paracolic gutter and across midline to the pelvis and right lower quadrant (red arrow). 


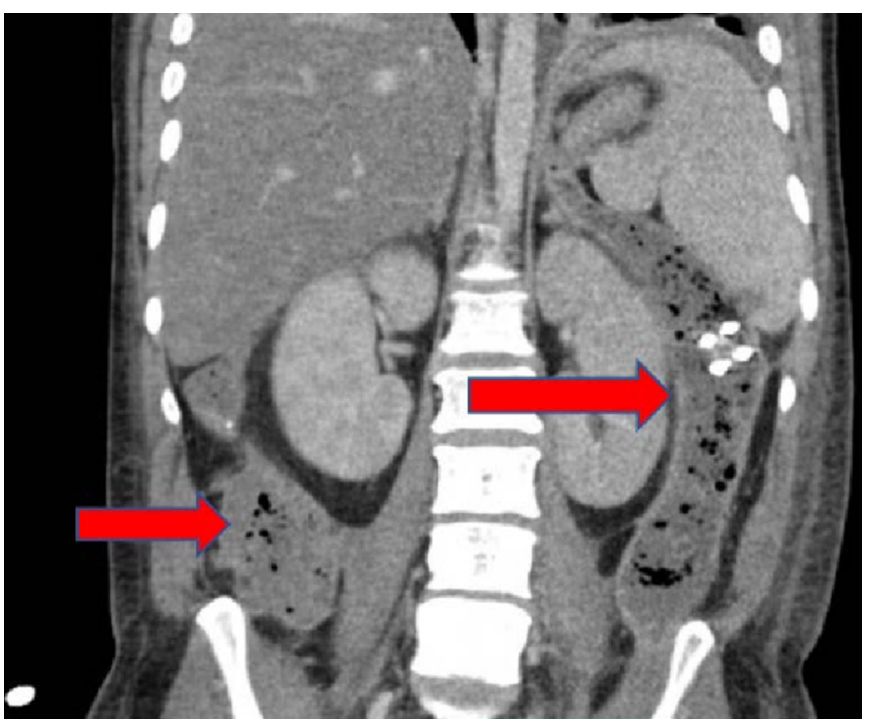

Figure 5 Collections in discontinuity in the left paracolic gutter and right lower quadrant (red arrows).

have the potential to be re-employed with escalation towards draining infected pancreatic necrosis. In 2010 the results of the trial demonstrated a number of benefits from the step-up approach over laparotomy. It randomized 88 patients to either an open necrosectomy or a step-up approach, defined as either a percutaneous drain or an endoscopic transgastric drainage followed by minimally invasive retroperitoneal necrosectomy if necessary. It showed that major complications such as new-onset organ failure, perforation, fistula or bleeding occurred in $12 \%$ of patients in the step-up group compared with $40 \%$ in the open group $(\mathrm{p}=0.002) .{ }^{5}$ The rate of death between the groups was similar $(19 \% \& 16 \%, \mathrm{p}=0.70)$ in the step-up and open groups, respectively, demonstrating that the step-up group was not undertreated. ${ }^{5}$ The PANTER trial also showed less organ failure, diabetes, and incisional hernia in the step-up group. Long-term follow-up of 73 patients at 86 months confirmed these benefits. ${ }^{12}$

In 2012 a small randomized trial (the PENGUIN trial) was performed comparing specifically endoscopic transgastric drainage versus surgical necrosectomy. This study randomized 20 patients and evaluated the inflammatory response as well as secondary endpoints inclusive of major complications or death. Patients in both groups underwent video-assisted retroperitoneal necrosectomy, if necessary. Ultimately, initiating with a transgastric endoscopic necrosectomy had reduced risk of major complications or death $(20 \%$ vs. $80 \%$; risk difference $0.60 ; 95 \%$ CI 0.16 to $0.80 ; \mathrm{p}=0.03) .{ }^{13}$

A number of retrospective studies have been performed in the last 5 years to compare the newer, less invasive procedures with laparotomy. A single institution study at the Liverpool Pancreas Center looked at 394 patients who underwent either a minimally invasive retroperitoneal pancreatic necrosectomy or open necrosectomy and also found that there were significant advantages to a minimally invasive approach. Total postoperative complications and organ failure were less frequent in the minimally invasive group (63.9\% vs. $81.7 \%) .{ }^{14}$ Furthermore, in a multivariant analysis, an independent mortality odds risk reduction of $73 \%$ was associated with the use of minimally invasive necrosectomy (OR 0.27; 95\% CI 0.12 to $0.57 ; \mathrm{p} \leq 0.001$ ). ${ }^{14}$

The German Pancreatitis Study Group performed a multicenter study in 2016 of 220 patients and found that only 44\% of patients in the step-up approach (percutaneous drainage, endoscopic drainage, with or without minimally invasive necrosectomy) had severe complications (sepsis, persistent multiorgan dysfunction, bleeding) compared with $73.3 \%$ of patients in the open group. ${ }^{15}$ Additionally, mortality was lower with $10.5 \%$ in the step-up group versus $33.3 \%$ in the open group. ${ }^{15}$

A group at a US academic medical center looked at 69 patients with walled-off pancreatic necrosis that required intervention and while they did not have the power to reach statistical significance, the trends found in the study showed an increased risk of in-hospital and 90-day mortality and increased length of stay in the open necrosectomy patients, as well as increased risk of periprocedural hemorrhage and incisional hernia development. ${ }^{16}$ In addition to this smaller study, a number of other small retrospective studies have been performed similarly with trends favoring a minimally invasive, step-up approach for necrotizing pancreatitis. ${ }^{17-19}$

In an effort to obtain a larger sample size and eliminate some of the confounding factors with retrospective studies, a recent, large observational study was performed analyzing the effect of minimally invasive strategies compared with each other and compared with an open procedure on the primary endpoint of death. ${ }^{20}$ This study included 1980 patients and was unique in data collection, identifying numerous studies and databases to combine original data, both published and unpublished. A significant association was found between the method of necrosectomy and death in patients who were determined to be at high risk of death (based on baseline characteristics including severity of pancreatitis). ${ }^{20}$ Looking at these patients within matched cohorts based on type of necrosectomy, both minimally invasive surgical necrosectomy compared with open necrosectomy and endoscopic necrosectomy compared with open necrosectomy had a lower risk of death ((risk ratio $0.70 ; 95 \%$ CI 0.52 to 0.94 ; $\mathrm{p}=0.02$ ) and (risk ratio $0.27 ; 95 \%$ CI 0.08 to $0.88 ; \mathrm{p}=0.03)$ )..$^{20}$

The benefits of an open surgical necrosectomy are better visualization of tissues for more selective debridement and hemorrhage control, enduring ostomy creation between walled-off necrosis and either stomach or small bowel, and ability to limit interventions to one procedure. ${ }^{21}$ Laparoscopic necrosectomy has also been evaluated as an alternative to open necrosectomy in small studies. Laparoscopy avoids the inflammatory response of a laparotomy, decreases hernia risk, and allows access to the entire abdomen potentially using a single intervention for definitive management. ${ }^{22}$ One retrospective study looked at patients who underwent either laparoscopic or open surgical necrosectomy and described a number of benefits to either surgical approach. ${ }^{21}$ Another small study successfully treated 14 of 23 patients with necrotizing pancreatitis laparoscopically and averted the need for laparotomy in all but one patient. ${ }^{22}$

\section{COMPARISON OF STEP-UP APPROACH OPTIONS}

In light of the benefits of less invasive procedures over laparotomy, laparotomy may be eliminated or delayed in many cases, necessary only as a rescue measure in decompensating patients. Many patients can be treated with percutaneous drainage alone. ${ }^{51023}$ Percutaneous catheter drainage is useful in reaching nearly the entire abdomen, short of locations such as the root of the mesentery and is less useful in treating very extensive collections. ${ }^{20}$ One large multi-institutional study looked closer at the specific management strategy of percutaneous drainage and suggests that more proactive upsizing and repeat drainage procedures can prevent necrosectomy even more than the current standard of less frequent, less aggressive drain checking and upsizing. ${ }^{24}$ Additionally, endoscopic drainage has been shown to 


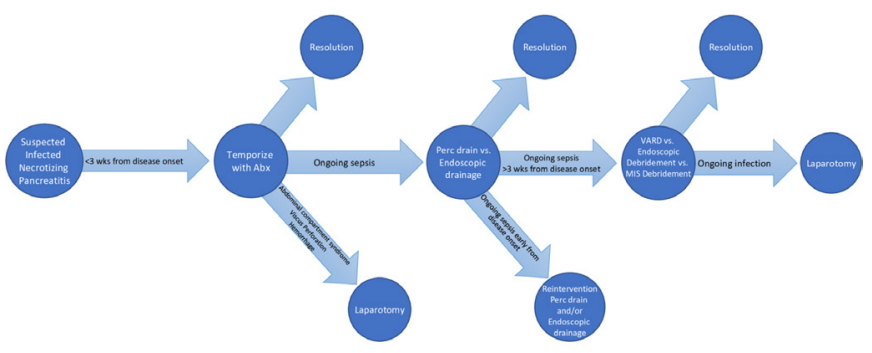

Figure 6 Generalized treatment flow with advent of step-up method for infected necrotizing pancreatitis. Abx, antibiotics; MIS, minimally invasive surgery; Perc, percutaneous; VARD, video-assisted retroperitoneal debridement.

be successful as the sole technique in $40 \%$ of patients in a recent study. ${ }^{25}$ National guidelines follow these developments, recommending most patients undergo either percutaneous catheter drainage or endoscopic drainage as a first intervention, ideally 4 weeks after initial presentation. ${ }^{2627}$

Many studies compare minimally invasive techniques as a group to open surgery and these may have sparse, underpowered subanalyses between minimally invasive groups. Relatively few studies exist that make direct comparisons between minimally invasive strategies. Two randomized trials have been performed to look specifically at minimally invasive strategies compared with each other.

The TENSION trial from the Dutch Acute Pancreatitis Study Group was designed to compare the two most common step-up minimally invasive techniques to each other with a primary endpoint of death or major complications. ${ }^{28}$ This study randomized 98 patients with infected pancreatic necrosis to receive initial management with either endoscopic drainage or percutaneous drainage, with escalation as necessary. The results of this study found the study groups to be comparable in primary outcomes of major complications or death (43\% vs. 45\%, relative risk $0.97,95 \%$ CI 0.62 to $1.51 ; \mathrm{p}=0.88) .{ }^{25}$ Differences between the groups were noted in the secondary endpoints of new-onset cardiovascular failure and persistent cardiovascular failure in the percutaneous group (relative risk 0.21, 95\% CI 0.09 to $1.07 ; \mathrm{p}=0.045$ and relative risk $0.23,95 \% \mathrm{CI} 0.05$ to $1.03 ; \mathrm{p}=0.32) .{ }^{25}$ In addition, pancreatic fistula was lower in the endoscopy group (5\% vs. $32 \%$, relative risk 0.15 , 95\% CI 0.04 to $0.62 ; \mathrm{p}=0.0011$ ) as well as a shorter hospital stay by 16 days on average (53 days (SD 47) vs. 69 days (SD 38), $\mathrm{p}=0.014) .^{25}$

The MISER randomized trial compares endoscopic step-up approach to minimally invasive surgery (defined as a laparoscopic necrosectomy or video-assisted retroperitoneal debridement) with primary endpoints of death or major complications. ${ }^{29}$ The primary endpoints occurred in $11.8 \%$ of the endoscopic group and $40.6 \%$ of the surgical group (risk ratio $0.29 ; 95 \%$ CI 0.11 to $0.80 ; \mathrm{p}=0.007$ ), however rate of death was comparable between groups. ${ }^{29}$ The result was most notably due to the $28.1 \%$ rate of pancreatic fistula in the surgical group compared with none in the endoscopic group $(p=0.001) .{ }^{29}$ In addition, the endoscopic group showed lower rates of systemic inflammatory response syndrome (SIRS), early resolution of pre-existing SIRS, and fewer patients with new-onset SIRS. ${ }^{29}$ This trial helps demonstrate the fundamental benefits of an endoscopic, natural orifice approach.

A small prospective cohort study in China prospectively enrolled 24 patients with infected pancreatic necrosis to either endoscopic transluminal drainage or percutaneous catheter drainage with the primary outcome of mortality or major complication. ${ }^{30}$ This group found that more patients could be treated with endoscopy as the sole interventional route as opposed to percutaneous drainage. ${ }^{30}$ Additionally, secondary endpoints of fistula and new-onset diabetes were less in the endoscopic group. ${ }^{30}$

\section{DISCUSSION}

Patients with infected necrotizing pancreatitis can be managed in a variety of ways. The decision on how to treat is largely based on the location of infected collections, extent of disease, availability of equipment and expertise in the various techniques. This is a heterogenous disease and precise treatment strategies are different for each patient based on a variety of criteria, however the goals of therapy are similar. The primary goal is to quickly decrease the SIRS response and assuage organ failure while inducing as little added stress as possible. The first step in reaching this goal is antibiotic administration. This could delay intervention until collections have matured and in some cases may avert the need for intervention entirely ${ }^{10}$ (see figure 6). The POINTER trial is underway to evaluate the use of antibiotics and delayed catheter drainage versus early catheter drainage when infection is suspected which will shed light on this aspect of therapy. Secondary goals in treatment are to minimize complications from the disease as well as the interventions to treat it. This includes pancreatic fistula, hernia, pancreatic exocrine and endocrine insufficiency, and avoiding undertreatment leading to a protracted disease course or multiple reinterventions.

The current trend in the literature leans towards favoring endoscopic drainage and endoscopic necrosectomy when possible. The downside of percutaneous drainage is that it enables extravasation of pancreatic enzymes into the surrounding tissues which contributes to pancreatic fistula formation. ${ }^{29} 31$ Endoscopy, on the other hand, does not require penetrating the skin. It is an approach that induces less stress and does not necessarily require general anesthesia. ${ }^{28}$ It does require collections to be located near the stomach or duodenal sweep which partially limits its application. While the majority of pancreatic collections are in the lesser sac, this method does not work for more distant collections, diffuse or multiple disconnected collections, and less commonly very large collections. ${ }^{32}$

Endoscopy as the primary approach to infected pancreatic collections is a relatively new strategy. In much of the earlier endoscopic literature, a technique using double pigtail plastic stents for drainage was described. In the last 10 years lumen-apposing metal stents have been developed and their use in draining infected pancreatic collections is promising with adoption by many practitioners. With this development the rates of successful endoscopic drainage without necrosectomy may increase as these stents have a larger diameter for drainage as well as flanges to prevent stent migration, however further studies are needed regarding safety and precise protocols for usage. ${ }^{33}$ Wide adoption of these procedures and the development of technical expertise will take time however may ultimately become the mainstay of treatment for infected necrotizing pancreatitis.

\section{CONCLUSION}

The management of infected necrotizing pancreatitis has changed dramatically during the last 20 years and continues to evolve with growing expertise, new techniques, and ongoing research efforts. It is clear, when possible, that a more conservative approach improves outcomes. This includes using antibiotics, delaying interventions, starting with less invasive interventional strategies when possible, and upgrading as necessary. Choosing 
the most appropriate treatment strategy is a multidisciplinary decision because it uses techniques that span the departments of gastroenterology, surgery, radiology, and critical care.

Contributors MKS reviewed the literature and personally wrote this review article as first author. KAD oversaw MKS's actions, and reviewed and edited this article. $K A D$ is the final author.

Funding The authors have not declared a specific grant for this research from any funding agency in the public, commercial or not-for-profit sectors.

Competing interests None declared.

Patient consent for publication Not required.

Provenance and peer review Commissioned; externally peer reviewed.

Open access This is an open access article distributed in accordance with the Creative Commons Attribution Non Commercial (CC BY-NC 4.0) license, which permits others to distribute, remix, adapt, build upon this work non-commercially, and license their derivative works on different terms, provided the original work is properly cited, appropriate credit is given, any changes made indicated, and the use is non-commercial. See: http://creativecommons.org/licenses/by-nc/4.0/.

\section{REFERENCES}

1. Underlying cause of death 1999-2017. data are from the multiple cause of death files, 1999-2017, as compiled from data provided by the 57 vital statistics jurisdictions through the vital statistics cooperative program. 2018.

2. Banks PA, Bollen TL, Dervenis C, Gooszen HG, Johnson CD, Sarr MG, Tsiotos GG, Vege SS, . Acute Pancreatitis Classification Working Group. Classification of acute pancreatitis--2012: revision of the Atlanta classification and definitions by international consensus. Gut 2013;62:102-11.

3. Werge M, Novovic S, Schmidt PN, Gluud LL. Infection increases mortality in necrotizing pancreatitis: a systematic review and meta-analysis. Pancreatology 2016;16:698-707.

4. Lankisch PG, Apte M, Banks PA. Acute pancreatitis. The Lancet 2015;386:85-96.

5. van Santvoort HC, Besselink MG, Bakker OJ, Hofker HS, Boermeester MA, Dejong CH, van Goor H, Schaapherder AF, van Eijck CH, Bollen TL, et al. A step-up approach or open necrosectomy for necrotizing pancreatitis. N Engl J Med 2010;362:1491-502.

6. Freeman ML, Werner J, van Santvoort HC, Baron TH, Besselink MG, Windsor JA, Horvath KD, vanSonnenberg E, Bollen TL, Vege SS, et al. Interventions for necrotizing pancreatitis: summary of a multidisciplinary consensus Conference. Pancreas 2012:41:1176-94

7. Mier J, León EL, Castillo A, Robledo F, Blanco R. Early versus late necrosectomy in severe necrotizing pancreatitis. Am J Surg 1997;173:71-5.

8. Hartwig Wet al. Reduction in mortality with delayed surgical therapy of severe pancreatitis. J Gastrointest Surg 2002;6): :481-7.

9. Besselink MGHet al. Timing of surgical intervention in necrotizing pancreatitis. Arch Surg 2007;142): :1194-201.

10. van Santvoort HC, Bakker OJ, Bollen TL, Besselink MG, Ahmed Ali U, Schrijver AM, Boermeester MA, van Goor H, Dejong CH, van Eijck CH, et al. A conservative and minimally invasive approach to necrotizing pancreatitis improves outcome. Gastroenterology 2011;141): :1254-63.

11. Loveday BPT, Petrov MS, Connor S, Rossaak JI, Mittal A, Phillips ARJ, Windsor JA, . Pancreas Network of New Zealand. A comprehensive classification of invasive procedures for treating the local complications of acute pancreatitis based on visualization, route, and purpose. Pancreatology 2011:11:406-13.

12. Hollemans RAet al. Superiority of step-up approach vs open necrosectomy in longterm follow up of patients with necrotizing pancreatitis. Gastroenterology 2018.

13. Bakker OJ, van Santvoort HC, van Brunschot $S$, Geskus RB, Besselink MG, Bollen $T L$, van Eijck CH, Fockens P, Hazebroek EJ, Nijmeijer RM, et al. Endoscopic transgastric vs surgical necrosectomy for infected necrotizing pancreatitis. JAMA 2012;307): :1053-61.

14. Gomatos IP, Halloran CM, Ghaneh P, Raraty MGT, Polydoros F, Evans JC, Smart HL, Yagati-Satchidanand R, Garry JM, Whelan PA, et al. Outcomes from minimal access retroperitoneal and open pancreatic necrosectomy in 394 patients with necrotizing pancreatitis. Annals of Surgery 2016;263): :992-1001.
15. Rasch S, Phillip V, Reichel S, Rau B, Zapf C, Rosendahl J, Halm U, Zachäus M, Müller M Kleger $A$, et al. Open surgical versus minimal invasive necrosectomy of the Pancreas-A retrospective multicenter analysis of the German pancreatitis Study Group. PLoS One 2016;11:e0163651

16. Jones JD, Clark CJ, Dyer R, Case LD, Mishra G, Pawa R. Analysis of a step-up approach versus primary open surgical necrosectomy in the management of necrotizing pancreatitis: experience in a cohort of patients at a US academic medical center. Pancreas 2018:47:1317-21.

17. Darrivere L, Lapidus N, Colignon N, Chafai N, Chaput U, Verdonk F, Paye F, Lescot T. Minimally invasive drainage in critically ill patients with severe necrotizing pancreatitis is associated with better outcomes: an observational study. Crit Care 2018;22:321.

18. Wroński M, Cebulski W, Witkowski B, Jankowski M, Kluciński A, Krasnodębski IW, Słodkowski M. Comparison between minimally invasive and open surgical treatment in necrotizing pancreatitis. J Surg Res 2017;210:22-31.

19. Tan V, Charachon A, Lescot T, Chafaï N, Le Baleur Y, Delchier J-C, Paye F. Endoscopic transgastric versus surgical necrosectomy in infected pancreatic necrosis. Clin Res Hepatol Gastroenterol 2014;38:770-6.

20. van Brunschot S, Hollemans RA, Bakker OJ, Besselink MG, Baron TH, Beger HG, Boermeester MA, Bollen TL, Bruno MJ, Carter R, et al. Minimally invasive and endoscopic versus open necrosectomy for necrotising pancreatitis: a pooled analysis of individual data for 1980 patients. Gut 2018;67:697-706.

21. Driedger Met al. Surgical transgastric necrosectomy for necrotizing pancreatitis: a single-stage procedure for walled-off pancreatic necrosis. Ann Surg 2018.

22. Parekh D. Laparoscopic-assisted pancreatic necrosectomy: a new surgical option for treatment of severe necrotizing pancreatitis. Arch Surg 2006;141:895-902.

23. van Baal MC, van Santvoort HC, Bollen TL, Bakker OJ, Besselink MG, Gooszen HG. Dutch Pancreatitis Study Group. Systematic review of percutaneous catheter drainage as primary treatment for necrotizing pancreatitis. Br J Surg 2011;98:18-27.

24. van Grinsven J, Timmerman P, van Lienden KP, Haveman JW, Boerma D, van Eijck CHJ, Fockens $P$, van Santvoort HC, Boermeester MA, Besselink MG, et al. Proactive versus standard percutaneous catheter drainage for infected necrotizing pancreatitis. Pancreas 2017:46:518-23.

25. van Brunschot $S$, van Grinsven J, van Santvoort HC, Bakker OJ, Besselink MG, Boermeester MA, Bollen TL, Bosscha K, Bouwense SA, Bruno MJ, et al. Endoscopic or surgical step-up approach for infected necrotising pancreatitis: a multicentre randomised trial. The Lancet 2018;391:51-8.

26. Working Group IAP/APA Acute Pancreatitis Guidelines. IAP/APA evidence-based guidelines for the management of acute pancreatitis. Pancreatology 2013;13(4 Suppl 2):e1-15.

27. Mowery NT, Bruns BR, MacNew HG, Agarwal S, Enniss TM, Khan M, Guo WA, Cannon JW, Lissauer ME, Duane TM, et al. Surgical management of pancreatic necrosis: a practice management guideline from the eastern association for the surgery of trauma. J Trauma Acute Care Surg 2017;83:316-27.

28. van Brunschot $S$, van Grinsven J, Voermans RP, Bakker OJ, Besselink MGH, Boermeester MA, Bollen TL, Bosscha K, Bouwense SA, Bruno MJ, et al. Transluminal endoscopic step-up approach versus minimally invasive surgical step-up approach in patients with infected necrotising pancreatitis (TENSION trial): design and rationale of a randomised controlled multicenter trial [ISRCTN09186711]. BMC Gastroenterol 2013;13:161.

29. Bang JY. An endoscopic transluminal approach, compared to minimally invasive surgery, reduces complications and costs for patients with necrotizing pancreatitis. Gastroenterology 2018

30. He W-H, Zhu Y, Zhu Y, Liu P, Zeng H, Xia L, Yu C, Chen H-M, Shu X, Liu Z-J, et al. The outcomes of initial endoscopic transluminal drainage are superior to percutaneous drainage for patients with infected pancreatic necrosis: a prospective cohort study. Surg Endosc 2017;31:3004-13.

31. Tsiotos GG, Smith CD, Sarr MG. Incidence and management of pancreatic and enteric fistulas after surgical management of severe necrotizing pancreatitis. Arch Surg 1995:130:48-52.

32. Traverso LW, Kozarek RA. Pancreatic necrosectomy: definitions and technique. J Gastrointest Surg 2005:9:436-9.

33. Boxhoorn L, Fockens P, Besselink MG, Bruno MJ, van Hooft JE, Verdonk RC, Voermans RP, . Dutch Pancreatitis Study Group. Endoscopic management of infected necrotizing pancreatitis: an evidence-based approach. Curr Treat Options Gastroenterol 2018; 16:333-44 